\title{
Are children with social anxiety disorder more likely than children with other anxiety disorders to anticipate poor social performance and reflect negatively on their performance?
}

Article

Accepted Version

Creative Commons: Attribution-Noncommercial-No Derivative Works 4.0

Halldorsson, B., Castelijn, S. and Creswell, C. (2019) Are children with social anxiety disorder more likely than children with other anxiety disorders to anticipate poor social performance and reflect negatively on their performance? Journal of Affective Disorders, 245. pp. 561-568. ISSN 01650327 doi: https://doi.org/10.1016/j.jad.2018.11.021 Available at https://centaur.reading.ac.uk/80427/

It is advisable to refer to the publisher's version if you intend to cite from the work. See Guidance on citing.

To link to this article DOI: http://dx.doi.org/10.1016/j.jad.2018.11.021

Publisher: Elsevier

All outputs in CentAUR are protected by Intellectual Property Rights law, including copyright law. Copyright and IPR is retained by the creators or other copyright holders. Terms and conditions for use of this material are defined in the End User Agreement. 


\section{www.reading.ac.uk/centaur}

\section{CentAUR}

Central Archive at the University of Reading

Reading's research outputs online 
Are children with social anxiety disorder more likely than children with other anxiety disorders to anticipate poor social performance and reflect negatively on their performance?

\section{Brynjar Halldorsson*, Saskia Castelijn and Cathy Creswell}

School of Psychology and Clinical Language Sciences, University of Reading

*Address for correspondence:

Brynjar Halldorsson,

School of Psychology and Clinical Language Sciences,

University of Reading, RG6 6AL, UK

Telephone: $+44(0) 1183788579$

Email: b.halldorsson@ @reading.ac.uk

Fax: +44 (0) 1183786715 


\begin{abstract}
Background: The cognitive theory of social anxiety disorder (SAD) suggests that adults with SAD have a tendency to anticipate poor social performance and reflect negatively on their performance following a social event. While a number of studies with socially anxious adults have supported the role of poor performance anticipation and post-event rumination in SAD, to date, only a few studies have addressed whether this also applies to children with SAD. Methods: Children (7-12 years) diagnosed with SAD $(\mathrm{n}=40)$, other anxious children $(\mathrm{n}=40)$ and non-anxious children $(n=34)$ were exposed to a social stressor speech task and their preand post-performance appraisals assessed, taking into account objective performance ratings. Results: Although observers rated some aspects of performance as significantly worse among children with SAD than children with other anxiety disorders, children with SAD were not more likely than their anxious or non-anxious peers to show a general bias in pre- or postperformance appraisals. Furthermore, children with SAD were just as likely as their anxious and non-anxious peers to recognize good performance but were more critical of themselves when their performance was poor.

Limitations: The speech task did not involve a same-age peer. Participants were relatively affluent group of predominantly non-minority status. Specificity for SAD in relation to other anxiety disorders remains unclear.

Conclusions: Focusing on counteracting pre- and post-event social performance appraisals may potentially be inappropriate for childhood SAD. Children with SAD might benefit from interventions that focus on helping them to become less critical of themselves after social interactions have not gone well.
\end{abstract}




\section{Highlights}

- Socially anxious children show poorer social performance than other anxious children

- Socially anxious children are not negatively biased about their social performance

- Children with SAD may be particularly self-critical when their performance does not go well

- Counteracting performance appraisals in childhood social anxiety may be inappropriate 


\section{Acknowledgements}

The authors would like to thank the participating families and staff in the Berkshire Child Anxiety Clinic at the University of Reading and Berkshire Healthcare NHS Foundation Trust, in particular Peter Cooper, Anna Alkozei, Sarah Cook, Amy Corcoran, Sue Cruddace, Rachel Gitau, Zoe Hughes, Jessica Karalus, Rebecca O'Grady, Ray Percy, Sarah Shildrick, Kerstin Thirlwall, and Lucy Willetts. In addition, we would like to thank Daniel Adam Gilson for his help with entering data.

\section{Funding source}

Prof. Creswell was funded by a MRC Clinician Scientist award (G0601874). Participants were recruited and assessed within treatment trials funded by the MRC-NIHR partnership (09/800/17) and the MRC (G0802326). Prof. Creswell and Dr. Halldorsson are currently funded by an NIHR Research Professorship to Prof. Creswell (NIHR-RP-2014-04-018).

\section{Contributors}

Author $\mathrm{BH}$ and $\mathrm{CC}$ designed the study and wrote the protocol. Author $\mathrm{BH}$ managed the literature searches and analyses. Author SC undertook data entry, aided with developing coding scheme, coded all videos and helped with literature searches. Author BH undertook statistical analyses with the assistance of CC. Author BH wrote the first draft of the manuscript. All authors contributed to and have approved the final version of the manuscript. 


\section{Introduction}

Social Anxiety Disorder (SAD) is one of the most common mental health problems, with up to $13 \%$ of the population meeting diagnostic criteria for SAD at any point in time (Beesdo et al., 2007; Kessler et al., 2005). Half of all affected people will first experience SAD by early adolescence (Kessler et al., 2005). As such, SAD is commonly diagnosed among clinically anxious pre-adolescent children seeking help for anxiety (e.g. 45\% (Waite \& Creswell, 2014); $82 \%$ (Kendall et al., 2010)). As well as disrupting children's social, emotional and academic development, SAD typically runs a chronic course, and is associated with adverse long-term consequences, including mood disorders, substance abuse and impaired educational and occupational prospects (Beesdo et al., 2007; Schutters et al., 2011).

Children with SAD are commonly treated with a transdiagnostic form of cognitive behavioural therapy (CBT) (e.g. Kendall \& Hedtke, 2006) because of the high rate of comorbidity and symptom overlap with other anxiety disorders (Kendall et al., 2010). Although the efficacy for transdiagnostic CBT is well established for childhood anxiety disorders in general (James, James, Cowdrey, Soler, \& Choke, 2015; Reynolds, Wilson, Austin, \& Hooper, 2012), for reasons that remain unclear, children with SAD are less likely to respond favourably compared to children with other anxiety disorders (e.g. remission rates of $40.6 \%$ vs. $72 \%$; Ginsburg et al., 2011). Furthermore, 30-50\% of children still retain their diagnosis following disorder specific interventions for childhood SAD (Beidel, Turner, \& Morris, 2000; Donovan, Cobham, Waters, \& Occhipinti, 2015; Öst, Cederlund, \& Reuterskiöld, 2015; Spence, Donovan, \& Brechman-Toussaint, 2000). These findings highlight the potential importance of understanding SAD-specific maintenance processes in children in order to improve treatment outcomes.

The most well-established maintenance models of adult SAD are those of Clark and Wells (1995) and Rapee and Heimberg (1997). Besides interpretation biases, safety-seeking 
behaviours and distorted self-images (mental representations), the models propose that anticipatory processing (AP) and post-event processing (PEP) play a key role in the maintenance of SAD. During AP, it is hypothesised that individuals with SAD retrieve and dwell on negative information about past social failures; shift their attention towards detailed monitoring of bodily symptoms of anxiety and negative thoughts; create a distorted selfimage or impression of how they think others perceive them; and, use their bodily symptoms of anxiety, negative thoughts, and distorted image/impression as evidence that they will ‘perform’ badly (Clark \& Wells, 1995; Hinrichsen \& Clark, 2003). In turn, AP increases anxiety about, and avoidance of, upcoming social events, therefore creating a vicious cycle that maintains the individual's social fears (Clark, 2005).

Clark and Wells (1995) conceptualize PEP as a ruminative process which individuals with SAD tend to engage in following a social interaction (Clark \& Wells, 1995; Heimberg, Brozovich, \& Rapee, 2010; Rapee \& Heimberg, 1997). According to the adult models, during PEP, individuals with SAD scrutinize their social performance in detail - guided by the negative thoughts, distorted self-images/mental representations, and feelings of anxiety that were processed during the social event itself (Clark, 2005; Clark \& Wells, 1995; Heimberg et al., 2010). As a result, the individual interprets their social interaction (or some aspect of it) as being more negative than it objectively was - providing him/her yet more 'proof' of their own social incompetence, resulting in greater social fears, avoidance of future social situations and anticipation of further social failure (Clark, 2005; Clark \& Wells, 1995; Dannahy \& Stopa, 2007; Rapee \& Heimberg, 1997).

While a number of studies with socially anxious adults have provided support for the SAD cognitive models' account of AP and PEP (e.g. Brozovich \& Heimberg, 2008; Dannahy \& Stopa, 2007; Gavric, Moscovitch, Rowa, \& McCabe, 2017; Rachman, Grüter-Andrew, \& Shafran, 2000), to date, their applicability to socially anxious children is mostly unclear. This 
is important to address as it is possible that AP and PEP - as described in the adult SAD models - may not apply directly to the maintenance of SAD in childhood. Both AP and PEP require complex cognitive operations and self-referential thinking and it remains unclear at what age or developmental level these processes emerge in children. For example, children typically don't develop the cognitive capacity to see themselves as other's see them until middle childhood (Cole, Jacquez, \& Maschman, 2001) and children and adults use different neurocognitive strategies when making self-referential judgements (Pfeifer, Lieberman, \& Dapretto, 2007).

Only a few studies have examined the specific constructs of AP and PEP as described in the adult SAD models in pre-adolescent children - with mixed findings (Schmitz, Krämer, Blechert, \& Tuschen-Caffier, 2010; Schmitz, Krämer, \& Tuschen-Caffier, 2011; Vassilopoulos, 2012). However, a number of studies have examined more general aspects of AP and PEP, in particular, whether socially anxious children have a tendency to anticipate poor social performance and whether they reflect negatively on their performance following social interactions. With regards to anticipated performance, consistent with the adult SAD models, most studies have reported a significant association between childhood social anxiety (or SAD) and poorer self-reported social performance predictions (Alfano, Beidel, \& Turner, 2006; Erath, Flanagan, \& Bierman, 2007; Morgan \& Banerjee, 2006; Spence, Donovan, \& Brechman-Toussaint, 1999; Tuschen-Caffier, Kuhl, \& Bender, 2011). However, only one study has examined disorder specificity by comparing children with SAD to children with other anxiety disorders, and whether expectancy of poor performance is specific to social situations. Creswell, Murray, and Cooper (2014) compared social performance predictions among children with $\mathrm{SAD}$, other-anxious and non-anxious children prior to a social stress (delivering a speech) and a physical challenge (exploring 'scary' items in a black box) and found no evidence of SAD specificity. 
With regards to post-performance appraisals, the majority of studies suggest that children with high social anxiety (or SAD) rate their social performance significantly worse than non-socially anxious children (Alfano et al., 2006; Schmitz et al., 2011; Tuschen-Caffier et al., 2011), although this has not always been supported (Spence et al., 1999). Critically, symptom/disorder specificity remains unclear as no studies have examined this association in relation to other non-social anxiety symptoms/disorders. In this paper, we consider whether low pre- and post-performance self-ratings are specific to childhood SAD in comparison to other childhood anxiety disorders.

An important consideration when examining social expectations and appraisals amongst children with SAD is their actual social competence - in other words, if children with SAD have negative beliefs about their performance is this a cognitive distortion or an accurate representation of reality? Developmental models of SAD propose that socially anxious children may be at particular risk of social failure due to social skills deficits (e.g. Rapee \& Spence, 2004; Spence \& Rapee, 2016). Consistent with this premise, existing disorder specific interventions for childhood SAD emphasize training children in social skills (e.g. Beidel et al., 2000; Spence et al., 1999). In contrast, adult SAD models propose that individuals with SAD do not lack social skills but have dysfunctional beliefs about their social skills which 'drive' counter-productive behaviours that interfere with social performance. Any observed performance deficits is, therefore, accounted for by the use of safety-seeking behaviours and self-focused attention as opposed to social skills deficits (McManus, Sacadura, \& Clark, 2008).

The majority of observational studies of social skills among children with SAD (with notable exceptions, e.g. Tuschen-Caffier et al., 2011) conclude that children with SAD have poorer 'social skills' than non-anxious children (Alfano et al., 2006; Beidel, Turner, \& Morris, 1999; Scharfstein \& Beidel, 2015). Notably, in the only study to address disorder 
specificity, Scharfstein and Beidel (2015) found that children with SAD had a significantly longer latency to initial speech than both children with GAD and non-anxious controls, but did not differ on other social behaviours (e.g. number of questions asked). It remains unclear, however, whether longer latency to initial speech was in fact an index of social skills or of inhibition in a socially stressful situation.

Taken together, there is evidence (albeit limited) that social anxiety or the presence of SAD is associated with lower performance self-ratings both prior to and after a social event but it remains unclear whether this association is specific to SAD. There is also some suggestion that $\mathrm{SAD}$ children's negative performance self-ratings may reflect reduced social competence, but it remains untested whether this is the case or whether the social beliefs of children with SAD reflect cognitive distortions. In support of the latter suggestion, studies with community populations have found that, compared to low socially anxious children, high socially anxious children feel significantly less socially skilled whereas observers are unable to distinguish the two groups (Cartwright-Hatton, Tschernitz, \& Gomersall, 2005).

\section{Study aims and hypotheses}

The aim of the current study was to extend previous research by comparing children with SAD, non-SAD forms of anxiety disorders (ANX) and non-anxious children (NAC) on self-ratings of their performance both prior to and after a social stressor speech task, taking into account objective performance ratings. The following hypotheses were tested based upon adult (Clark \& Wells, 1995; Rapee \& Heimberg, 1997) and developmental models of SAD (Rapee \& Spence, 2004; Spence \& Rapee, 2016):

1. In line with the adult models, children with SAD will anticipate worse social performance than both ANX and NAC children.

2. In line with the adult models, children with SAD will rate their social performance lower than both ANX and NAC children. 
3. In line with developmental models of childhood SAD, children with SAD will be rated by observers as exhibiting poorer social performance than both ANX and NAC children.

4. In line with the adult models, children with SAD (compared to ANX and NAC children) will anticipate poorer performance and more negatively appraise their actual performance, even after actual observer ratings have been taken into account.

\section{Methods}

\section{Participants}

One-hundred and fourteen children aged 7-12 years took part in the study. The participants were $40(35 \%)$ children with a principal diagnosis of SAD, $40(35 \%)$ children with a diagnosed anxiety disorder other than SAD (ANX), and 34 (30\%) non-anxious control participants (NAC).

Children in both anxiety disorder groups were recruited following a referral by local health and education service personnel to a specialist anxiety clinic and research centre in the UK. Children were only included in the SAD group if they had a primary diagnosis of SAD. Primacy was allocated to the disorder given the highest clinical severity ratings (CSR) based on the Anxiety Disorders Interview Schedule for DSM-IV for Children - Child and Parent Versions (ADIS-C/P; Silverman \& Albano, 1996). Children were not excluded from the SAD group on the basis of comorbid diagnoses so as to represent a typical clinical population. Children were included in the ANX group if they met diagnostic criteria for an anxiety disorder other than SAD as their principal diagnosis, and they were excluded if they met criteria for a comorbid diagnosis of SAD. Other exclusion criteria across both clinical groups were, a significant physical or intellectual impairment; current prescription of psychotropic medication; and, previous receipt of six or more sessions of CBT (i.e. treatment specifically targeting the processes under investigation). 
Non-anxious control participants were volunteers, recruited through invitation letters, sent predominantly to schools and local after-school clubs, specifically asking for children to form a non-anxious comparison group. The inclusion criteria were that children must be between 7 and 12 years of age, and have anxiety levels within the normal range based on parent and child report. Exclusion criteria were a significant physical or intellectual impairment (where this would impede reliable completion of measures), and current prescription of psychotropic medication. Children in the NAC group were screened on the basis of child and parent (primary caregiver) report on the Spence Children's Anxiety Scaleparent and child versions (Nauta et al., 2004; Spence, 1998), as both measures have been found to discriminate between clinically anxious and non-anxious groups and normative data are available (e.g. Nauta et al., 2004; Spence, 1998). Where children scored above the normal range (i.e., in the 'borderline' or 'abnormal' categories) they were not invited for further inclusion in the study, but were provided with resources to help them to access support. Families in the NAC group were given gift tokens in exchange for taking part.

\section{Structured Diagnostic Interview with Children and Parents}

Children were assigned a diagnosis on the basis of the ADIS-C/P (Silverman \& Albano, 1996). Where children met symptom criteria for a diagnosis, based on either parent or child report, they were assigned a CSR score ranging from 0 (complete absence of psychopathology) to 8 (severe psychopathology). Only those who met the symptom criteria with a CSR of 4 (moderate psychopathology) or more were considered to meet diagnostic criteria. Assessors (psychology graduates) were trained on the standard administration and scoring of the ADIS-C/P through verbal instruction, listening to assessment audio-recordings and participating in diagnostic consensus discussion. The first 20 interviews conducted were then discussed with a consensus team, led by an experienced diagnostician (consultant clinical psychologist). The assessor and the consensus team independently allocated 
diagnoses and CSRs. Following the administration of 20 child and 20 parent interviews, inter-rater reliability for each assessor was checked, and if assessors achieved reliability of at least .85 they were then required to discuss just one in six interviews with the consensus team to prevent inter-rater drift. Overall reliability for the team was excellent. Reliability for the presence or absence of diagnosis was kappa $=.98$; and for the CSR intra-class correlation $=$ 99.

Measures

Spence Children's Anxiety Scale-parent and child versions (Spence, 1998; SCAS-p/c)

The SCAS-p/c was administered to assess parent and child reported symptoms of anxiety. Both the parent and child version require the respondent to rate how often the child experiences each of the 38 anxiety symptoms on a 4-point scale from 0 (never) to 3 (always). The SCAS-p/c has demonstrated high internal reliability and concurrent validity (Spence, 1998), with children from 7 years of age (Muris, Schmidt, \& Merckelbach, 2000). Both versions have demonstrated concurrent validity and internal consistency (Nauta et al., 2004; Spence, 1998). Internal reliability based on data from the current sample was acceptable (Cronbach's alpha $\alpha=.94$ for parent report; $\alpha=.93$ for child report).

Social Stress Task - Presentation

Children were asked to give a 3 to 5 minute presentation to a research assistant and recorded on a video camera. Prior to the task, they were given a choice of topics to talk about ('My hobbies', 'My typical day', 'My family’ or 'My favourite holiday') and were allowed five minutes to prepare their speech (with parent support) (see further Creswell, Apetroaia, Murray, \& Cooper, 2013).

Pre- and Post-performance ratings

Before starting to prepare for the task, children were asked to provide ratings to indicate: 'How well they thought they would do the presentation' $(0=$ Not well at all $-10=$ 
very, very well; Pre-performance). Upon completing the task, children were asked to provide ratings to indicate: 'How well they thought they did the presentation' $(0=$ Not well at all -10 = very, very well; Post-performance).

\section{Observational coding scheme}

Recorded conversations were observed by an independent rater (psychology graduate). To assess children's speech performance, the speeches were rated for (i) Fluency (e.g. whether the speech was constant, fluent without hesitation and easily understood), (ii) Professionalism (e.g. whether the child displayed appropriate emotions and pitch, allowing the presentation to run smoothly) and (iii) Structure (e.g. whether the child presented the speech in the form of a presentation, allowing it to flow nicely with a nice structure which could be clearly seen as planned).

For reliability purposes, a second rater (psychology graduate) watched and coded thirty $(26 \%)$ videos independently in order to assess inter-rater reliability which was high across scale that was coded $(\mathrm{ICC}=.98-.99)$. Correlations for the rating scales ranged from .71 to .81 . Both raters were blind to experimental group condition and given minimal background information regarding the study. The coding scheme is available on request from the first author.

\section{Procedure}

Parents of all participants gave informed consent and children provided assent. All procedures received University and National Health Service ethical approval. Children with anxiety disorders and their parents were seen for an initial assessment, to complete standardized questionnaires and undertake the diagnostic interview. If children met criteria for either the SAD or ANX groups they were invited to take part in the research (which was conducted as part of a broader assessment of factors associated with the development of childhood anxiety disorder) before starting treatment. For the non-anxious control 
participants, parents were mailed the SCAS-p in advance of the meeting. If parents reported that children scored within normal limits on the SCAS-p, an appointment was scheduled with the help of a research assistant.

\section{Results}

\section{Preliminary analyses}

Preliminary analyses were conducted to identify potential confounding variables. Table 1 shows the participants' demographic characteristics. There were similar numbers of female and male participants in each group and groups did not differ on child age (in months) or ethnicity. However, the groups did differ on socio-economic status (SES) with significantly fewer children among the SAD group coming from families that were classified as higher/professionals according to the national statistics socio-economic classification criteria (HMSO, 2005). Further analyses, therefore, controlled for SES in relation to the relevant dependent variables. As SES, did not have a significant association in any of the models, the results below are presented unadjusted for SES.

Table 1. Demographics by group

\begin{tabular}{ccccc}
\hline & $\begin{array}{c}\text { SAD } \\
(\mathrm{n}=40)\end{array}$ & $\begin{array}{c}\text { ANX } \\
(\mathrm{n}=40)\end{array}$ & $\begin{array}{c}\text { NAC } \\
(\mathrm{n}=34)\end{array}$ & $\begin{array}{c}\text { Statistics } \\
\text { Child gender (\% boys) }\end{array}$ \\
\hline 50 & 55 & 61.8 & $\chi^{2}(2)=1,031, p=.597$ \\
Child age in months, M (SD) & 127.2 & 120.4 & 119.4 & $F(2,101)=2.182, p=.118$ \\
Child ethnicity (\% white) & 90 & 80 & 73.5 & $\chi^{2}(2)=3.420, p=.181$ \\
SES (\% higher / professional) & 54.8 & 81.6 & 81.3 & $\chi^{2}(2)=7.757, p=.021$ \\
\hline
\end{tabular}

Note. $\mathrm{M}=$ mean; $\mathrm{SD}=$ standard deviation; $\mathrm{SES}=$ socio-economic status

Table 2 shows the frequency of children's anxiety disorders, PTSD and mood disorder (either major depressive disorder and/or dysthymia), together with their scores on questionnaires and comorbid diagnoses. Compared to the ANX group, children with SAD were significantly more likely to have comorbid generalized anxiety disorder (GAD), 
externalizing disorder, and mood disorders. Children did not differ significantly on the presence of any other diagnosis. For the examination of specificity to SAD, where significant group differences emerged, we conducted sensitivity analyses by excluding children from both clinical groups with comorbid (i) GAD, (ii) externalizing disorder, and (iii) mood disorders (see further below).

Table 2. Frequency of comorbid diagnosis for clinical groups and questionnaire scores for all groups

$\begin{array}{cccc}\text { SAD }(\mathrm{n}=40) & \text { ANX }(\mathrm{n}=40) & \text { NAC (34) } & \text { Statistics } \\ 50(20) & 50(20) & - & \chi^{2}(1)=.00, p=1.00 \\ 72.5(29) & 30(12) & - & \chi^{2}(1)=14.459, p<.001 \\ 20(8) & 2.5(1) & - & \chi^{2}(1)=6.135, p=.029^{\wedge} \\ 0(0) & 7.5(3) & - & \chi^{2}(1)=3.117, p=.241^{\wedge} \\ 0(0) & 2.5(1) & - & \chi^{2}(1)=1.013, p=1.00^{\wedge} \\ 7.5(3) & 7.3(3) & - & \chi^{2}(1)=.00, p=1.00^{\wedge} \\ 47.5(19) & 52.5(21) & - & \chi^{2}(1)=.20, p=.655 \\ 10(4) & 0(0) & - & \chi^{2}(1)=4,211 p=.116^{\wedge} \\ 5(2) & 10(4) & - & \chi^{2}(1)=.721, p=.675^{\wedge} \\ 2.5(1) & 0(0) & - & \chi^{2}(1)=1.013, p=1.00^{\wedge} \\ 45.0(18) & 17.5(7) & - & \chi^{2}(1)=7.040, p=0.01\end{array}$

Sep. Anx. Dis. \% (n)

GAD \% (n)

Mood disorder \% (n)

Panic dis. w/o agoraph. \% (n)

Panic dis. with agoraph. \% (n)

Agoraph. w/o panic dis. \% (n)

Specific Phobia \% (n)

OCD \% (n)

Anxiety disorder

NOS \% (n)

PTSD \% (n)

Externalizing disorder

SCAS-social-p, M (SD)

SCAS-social-c, M (SD)

SCAS-p total, M (SD)

SCAS-c total, M (SD)

SCAS-no social-p, $\mathrm{M}$ (SD)

SCAS-no social-c, $\mathrm{M}(\mathrm{SD})$

\begin{tabular}{|c|c|c|c|}
\hline $11.03(3.82)^{\mathrm{a}}$ & $6.44(3.49)^{\mathrm{a}}$ & $3.38(2.09)^{\mathrm{a}}$ & $\begin{array}{c}F(2,102)=48.999 \\
p<.001\end{array}$ \\
\hline $8.21(4.55)^{\mathrm{a}, \mathrm{b}}$ & $4.45(3.44)^{\mathrm{a}}$ & $4.53(3.02)^{b}$ & $\begin{array}{c}F(2,105)=12.080 \\
p<.001\end{array}$ \\
\hline $45.19(18.54)^{\mathrm{a}}$ & $36.84(14.80)^{\mathrm{a}}$ & $13.24(5.75)^{\mathrm{a}}$ & $\begin{array}{c}F(2,104)=47.287 \\
p<.001\end{array}$ \\
\hline $42.24(23.43)^{\mathrm{a}}$ & $32.68(16.98)^{b}$ & $27.52(12.58)^{\mathrm{a}, \mathrm{b}}$ & $\begin{array}{c}F(2,106)=5.897 \\
p=.004\end{array}$ \\
\hline $34.51(16.08)^{\mathrm{a}}$ & $30.17(13.49)^{\mathrm{b}}$ & $9.85(4.70)^{\mathrm{a}, \mathrm{b}}$ & $\begin{array}{c}F(2,102)=38.285 \\
p<.001\end{array}$ \\
\hline $34.03(19.35)^{\mathrm{a}}$ & $28.24(14.46)^{\mathrm{b}}$ & $23.66(10.88)^{\mathrm{a}, \mathrm{b}}$ & $\begin{array}{c}F(2,105)=3.393 \\
p=.022\end{array}$ \\
\hline
\end{tabular}


Note. Sep. Anx. Dis.= separation anxiety disorder; Mood disorder $=$ either major depressive episode and/or dysthymia; Anxiety disorder NOS = Anxiety disorder not otherwise specified; Panic dis. w/o agorapho. $=$ Panic disorder without agoraphobia; Externalizing disorder $=$ Attention-deficit hyperactivity disorder (combined type, inattentive type and hyperactive/impulsive type), Oppositional defiant disorder or Conduct disorder; SCAS-p = Spence children's anxiety scale-parent report; SCAS$\mathrm{c}=$ Spence children's anxiety scale-child report; SCAS-social- $\mathrm{p}=$ Spence children's anxiety scalesocial phobia subscale-parent report; SCAS-social-c = Spence children's anxiety scale social phobia subscale-child report; SCAS-no social-p = Spence children's anxiety scale excluding social phobia subscale-parent report; SCAS-no social-c = Spence children's anxiety scale excluding social phobia subscale-child report; $\mathrm{M}=$ mean; $\mathrm{SD}=$ standard deviation; ${ }^{\mathrm{a}}$ and ${ }^{\mathrm{b}}$ denote groups that significantly differ on the basis of post-hoc analyses; ${ }^{\wedge}=$ When expected cell counts was very small we reported the value from the chi-square and the p-value from the Fisher's exact test.

As expected, significant group differences were found on scores of parent and child reported social anxiety (see Table 2). That is, for the SCAS-p social anxiety subscale, children with SAD had significantly higher levels of social anxiety compared to both groups, and children with ANX had significantly greater social anxiety than NAC children. For the SCAS-c social anxiety subscale, children with SAD also self-reported significantly greater social anxiety than both other groups (who did not differ). There were also significant group differences on SCAS-p total anxiety scores, which reflected significantly higher anxiety in the SAD group compared to both other groups, as well as a significantly higher anxiety in the ANX group compared to the NAC group; and on the SCAS-c total anxiety score where children with SAD self-reported significantly greater anxiety than the NAC children and differences with scores of the ANX children approached significance $(p=.076)$. Further examination indicated that differences between the SAD and ANX groups on SCAS-p/c totals reflected the group differences in the social anxiety subscale scores, as these differences were no longer significant after subtracting the social anxiety subscale score from the SCAS total (SCAS-no social-p/c), although both groups continued to differ significantly from the NAC group.

Finally, analyses were also conducted to examine whether the children perceived the speech task to be stressful. Based on children's self-reported anxiety prior to the task (using a 10 point scale; $0=$ no anxiety, $10=$ severe anxiety), all groups rated the speech task as (at 
least) mildly stressful (see Table 3) and no significant group differences emerged (Analysis of Variance (ANOVA); $F(2,113)=2.491, p=.087)$ ).

Children's perceptions of performance pre-and post-social task (Hypothesis 1 and 2)

To address whether children with SAD anticipated worse performance and rated their performance worse than both ANX and NAC children following the social stress task, two ANOVAs were conducted. Children's pre- or post-performance ratings (see Table 3) were entered as the dependent variables and group (SAD vs. ANX vs. NAC) as the independent variable. In contrast to the adult SAD models, no significant group differences emerged for children's anticipated performance $\left(F(2,111)=.511, p=.601, \eta^{2}=.01\right)$ or post-performance ratings $\left(F(2,111)=1.162, p=.317, \eta^{2}=.02\right)$.

Table 3. Group differences in children's performance self-ratings

\begin{tabular}{lllllll}
\hline & \multicolumn{2}{c}{ SAD $(\mathrm{n}=40)$} & \multicolumn{2}{c}{ ANX $(\mathrm{n}=40)$} & \multicolumn{2}{c}{ NAC $(\mathrm{n}=34)$} \\
\hline & Pre-task & Post-task & Pre-task & Post-task & Pre-task & Post-task \\
\hline Anxiety (M, SD) & 4.83 & & 3.38 & & 3.79 & \\
& $(3.19)$ & & $(2.85)$ & & $(2.84)$ & \\
Performance (M, & 5.20 & 5.60 & 5.83 & 6.58 & 5.47 & 5.68 \\
SD) & $(2.80)$ & $(3.50)$ & $(3.12)$ & $(3.22)$ & $(2.25)$ & $(2.58)$ \\
\hline
\end{tabular}

Note. Lower score indicates worse performance expectancy

\subsection{Observers' perceptions of children's performance (Hypothesis 3)}

A Multivariate Analyses of Variance (MANOVA) was performed to examine whether observers rated the performance of children with SAD poorer than both ANX and NAC children. The dependent variables were the observers' ratings and group was the independent variable. Using Pillai's trace, there were significant effects of group on observers' ratings $F(6,220)=2.991, p<.01 ;$ partial $\eta^{2}=.075$. Separate univariate ANOVAs (with post-hoc tests and Bonferroni corrections) revealed that children with SAD were rated by observers as significantly poorer on Professionalism and Structure than the ANX group but did not differ from the NAC group. No other significant group differences emerged (see Table 4). 
Table 4. Observers' ratings

\begin{tabular}{lccc}
\hline & SAD $(\mathbf{n = 4 0})$ & ANX $(\mathbf{n}=\mathbf{4 0})$ & NAC $(\mathbf{n = 3 4})$ \\
\hline Fluency (mean, SD, range) & $3.15(1.37), 1-6$ & $2.67(0.86), 1-5$ & $3.13(1.00), 1-6$ \\
Professionalism (mean, SD, range) & $2.84(1.47), 1-6^{\mathrm{a}}$ & $2.04(0.81), 1-4^{\mathrm{a}}$ & $2.24(1.20), 1-6$ \\
Structure (mean, SD, range) & $3.35(1.70), 1-6^{\mathrm{a}}$ & $2.45(1.32), 1-5^{\mathrm{a}}$ & $2.88(1.53), 1-6$ \\
\hline
\end{tabular}

Note. Superscript letters refer to pairwise comparisons. Means that share superscripts within rows are significantly different, $\mathrm{p}<.05$; higher scores indicate worse performance.

Follow-up sensitivity analyses were conducted by comparing the groups on observers' ratings of Professionalism and Structure after excluding children with GAD $(n=41)$, externalizing disorders $(n=25)$ and Mood disorders $(n=9)$ from the SAD and ANX groups. Differences in observers' ratings remained significant across all these follow-up analyses when children with Mood Disorders and externalizing disorders were excluded and approached significance $(p=.07)$ when children with GAD were excluded.

Accuracy of children's performance ratings relative to objective observers (Hypothesis 4)

Finally, analysis of Covariance (ANCOVA) were carried out in two stages in order to address whether children with SAD were more likely than both ANX and NAC children to anticipate worse performance and negatively appraise their performance even after actual observer ratings were taken into account. We first investigated anticipated performance with group (SAD vs. ANX vs. NAC) as the independent variable, children's pre-performance selfratings as the dependent variable and each of the observers' ratings (Fluency, Professionalism and Structure) entered separately as covariates. We then examined post-performance ratings, where children's post-performance self-ratings were entered as the dependent variable and, as before, group was entered as the independent variable and observers' ratings as covariates. In addition, observer ratings $\mathrm{x}$ group interactions were entered as covariates. For anticipated performance, none of the covariates were significantly associated with children's preperformance self-ratings (Fluency, $F(2,110)=.490, p=.614$, partial $\eta^{2}=.009$; Professionalism, $F(2,110)=.406, p=.667$, partial $\eta^{2}=.007$; Structure $F(2,110)=.760, p=$ .470 , partial $\eta^{2}=.014$ ). For post-performance ratings, the covariates Fluency, Professionalism 
and Structure were significantly associated with children's post-performance self-ratings. No significant group differences emerged $(p>.41)$, however, the interaction between observer ratings and group was statistically significant (Fluency: $F(3,110)=3.764, p=.013$, partial $\eta^{2}$ $=.093$; Professionalism: $F(3,110)=4.009, p=.009$, partial $\eta^{2}=.099$; Structure: $F(3,110)=$ 3.690, $p=.014$, partial $\left.\eta^{2}=.091\right)$. As shown in Figure 1, children with SAD gave similar performance ratings to the other groups when their performance was objectively rated to be good but rated their performance as poorer than both other groups when their speeches were objectively rated as poor in terms of Fluency, Professionalism and Structure. Follow-up sensitivity analyses revealed that the interaction effects remained significant when children with externalizing disorders were excluded; this was not the case when children with GAD or mood disorders (except for Structure) were excluded, but the effect sizes were the same or similar (Table 5).

Table 5. Interaction effects - sensitivity analyses

\begin{tabular}{lccc}
\hline & $\begin{array}{c}\text { Excluding } \\
\text { GAD }\end{array}$ & $\begin{array}{c}\text { Excluding } \\
\text { Externaliz. dis. }\end{array}$ & $\begin{array}{c}\text { Excluding } \\
\text { Mood dis. }\end{array}$ \\
\hline Group x Fluency & $F(2,36)=1.759$, & $F(2,52)=3.454$, & $F(2,68)=2.479$, \\
& $p=.187, \eta^{2}=.09$ & $p=.039, \eta^{2}=.12$ & $p=.091, \eta^{2}=.07$ \\
Group x Professionalism & $F(2,36)=2.265$, & $F(2,52)=3.255$, & $F(2,68)=2.266$, \\
& $p=.118, \eta^{2}=.11$ & $p=.047, \eta^{2}=.11$ & $p=.112, \eta^{2}=.06$ \\
Group x Structure & $F(2,36)=1.852$, & $F(2,52)=5.123$, & $F(2,68)=3.329$, \\
& $p=.172, \eta^{2}=.09$ & $p<.01, \eta^{2}=.17$ & $p=.042, \eta^{2}=.09$ \\
\hline
\end{tabular}


Figure 1. Children's self-ratings and observer ratings of social performance

Structure

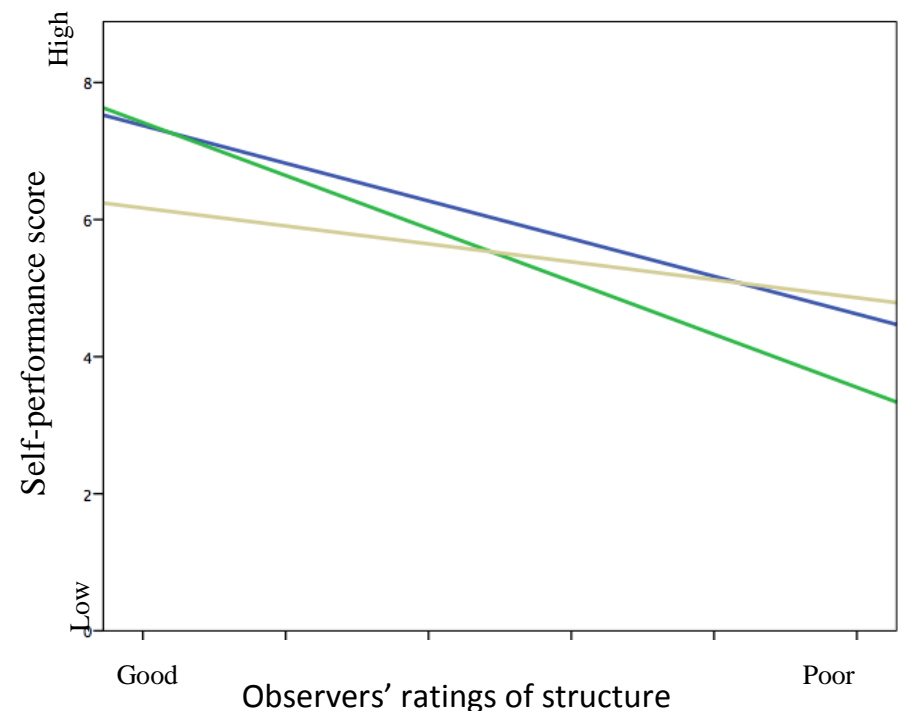

Fluency

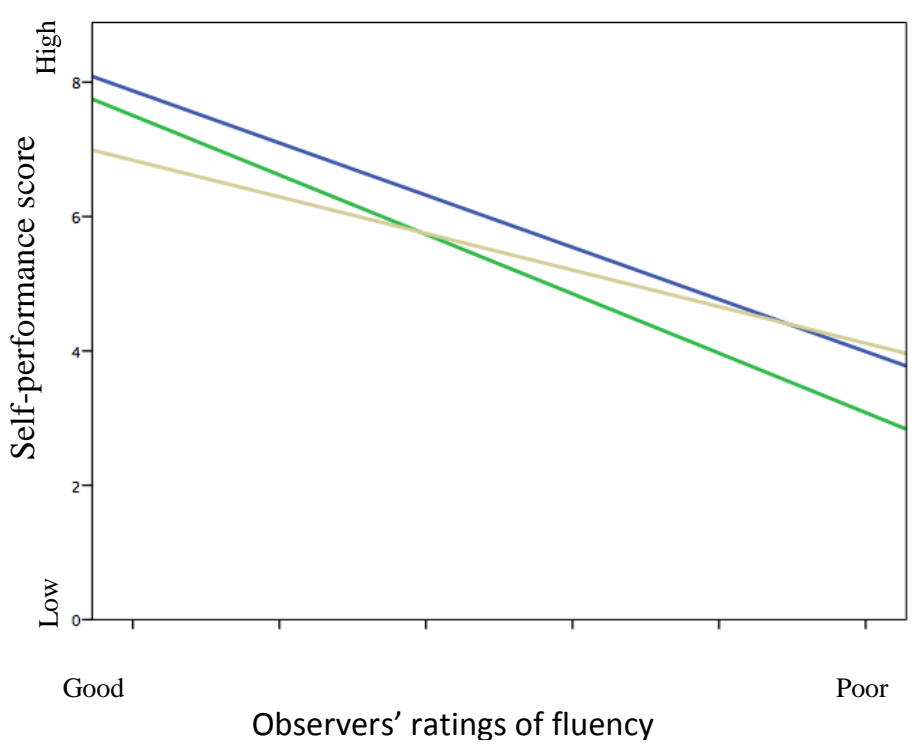

Professionalism

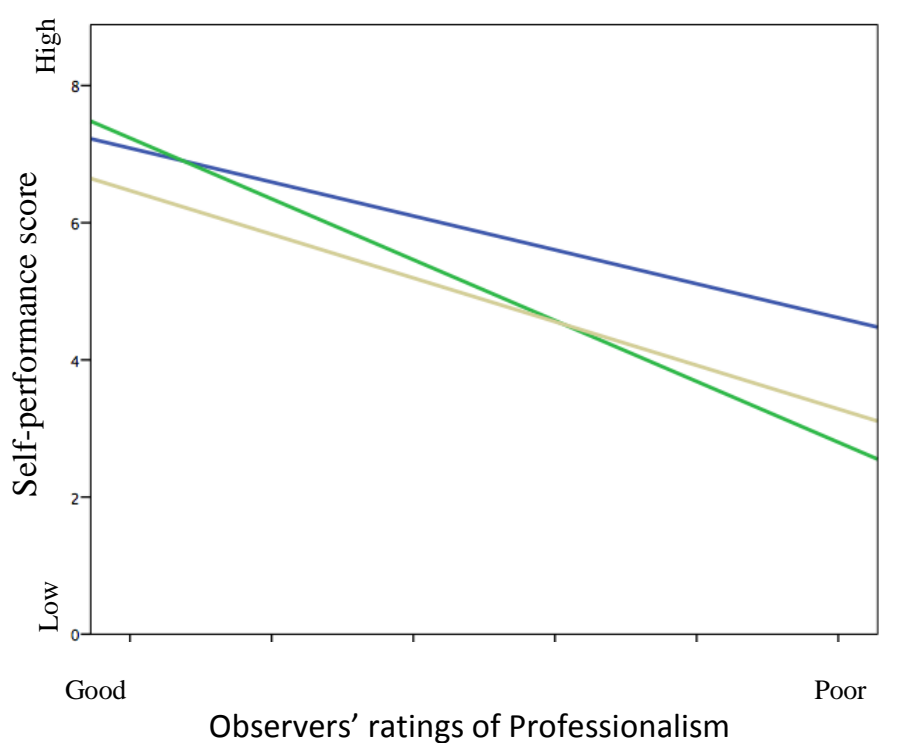

\section{SAD}

ANX

NAC

\section{Discussion}

In contrast to the adult cognitive models of SAD's assertions that individuals with SAD anticipate poor social performance (Clark \& Wells, 1995; Rapee \& Heimberg, 1997), in this study - and in line with Creswell et al. (2014) - children with SAD did not anticipate worse social performance than children with other anxiety disorders or non-anxious children. 
Furthermore, children with SAD did not generally underestimate past social performance and were just as likely as other anxious and non-anxious children to recognize when they performed well. However, the findings suggest that children with SAD gave themselves 'a harder time' than children with other anxiety disorders and non-anxious children when their social performance was noticeably poor. That is, we found that children with SAD were more likely than their anxious and non-anxious peers to be critical of themselves if, for example, they hesitated or stuttered. It will be important to understand why children with SAD may be more self-critical than their peers. Environmental factors, such as, school environment, peer relationships and family factors may play a role here.

In line with the developmental model's assumption that children with SAD have ‘social skills deficits' (Rapee \& Spence, 2004; Spence \& Rapee, 2016), observers were more likely to identify performance deficits among children with SAD compared to children with other anxiety problems (although differences with non-anxious children were nonsignificant). Specifically, the observers reported that children with SAD were significantly less likely than children with ANX to display appropriate emotions or give a well structured speech. However, children with SAD were rated as indistinguishable from their other anxious peers in fluency, highlighting that children with SAD may have problems with some - but not all - aspects of social skill. Similar findings were reported in the only one previous observational study comparing social skills among children with SAD and children with other anxiety disorders: Scharfstein and Beidel (2015), found that whilst children with SAD took significantly longer time to start talking and spoke less than children with GAD whilst playing a video game with an unfamiliar peer, they made a similar amount of questions and exclamations.

Critically, neither this study or Scharfstein and Beidel (2015), are able to distinguish between social skills deficits and anxiety-induced performance deficits. That is, even though 
both studies found that some aspects of social behaviour was objectively poor among children with SAD, it is unclear whether this resulted from a lack of knowledge (i.e. skill) versus inhibition of the expression of skilful behaviour due to social anxiety, or some combination of the two (Hopko, McNeil, Zvolensky, \& Eifert, 2002). For example, it is possible that children with SAD are fully capable of appropriate social behaviour but under social threat become excessively self-focused and engage in safety-seeking behaviours in an attempt to lower their perceived threat, which has the unintended effect of interfering with performance and making them less likeable (Clark \& Wells, 1995). Indeed, findings from the adult literature have directly linked the use of self-focused attention and safety-seeking behaviours with poor social performance ratings among observers (McManus et al., 2008).

It is also possible that the group differences that we identified were driven by a subgroup of children with SAD who have underlying social communication difficulties. Indeed, there is some suggestion from two recent questionnaire studies that social communication deficits are limited to a subgroup (approximately 8-10\%) of children with SAD (Halls, Cooper, \& Creswell, 2015; Pearcey et al., 2018). Future research must consider carefully that any study which observes children's responses within a socially challenging situation will be prone to difficulty in interpretation (Halldorsson \& Creswell, 2017). Studies using multi-method approaches to examine the underlying social communication deficits will make an important contribution to our understanding of which factors may drive the observed social responses and potential social skills deficits among children with SAD.

Strengths of this study include a clinical population which allowed for the specific consideration of childhood SAD, diagnosed on the basis of systematic and reliable assessments. In addition, this study used both subjective and objective measures of children's social performance. Further, the study adds to a very limited literature examining children's performance predictions across different anxiety disorders and is the first study to examine 
post-performance appraisals among children with SAD in relation to other common anxiety disorders.

\section{Limitations}

Several limitations must be considered. Of particular note, we used a general and global measure of children's self-reported pre- and post-social performance ratings. This was done to minimize burden and also to not direct the children's attention to any specific aspects of their social communication. As a result, it is unclear what specific performance factors led to the children's judgements and if they were the same as the ones identified by the observers (who were asked to make judgements of narrowly selected 'social skills'). The speech task that was employed in the study involved an adult observer, not a same-age peer. This is important as diagnostic criteria require children's social anxiety to be present in peer relationships (American Psychiatric Association, 2013) and previous studies have suggested that the type of audience may have had an effect on how children with SAD rate their social performance (e.g. Alfano et al., 2006). Other limitations include that our sample were predominantly Caucasian and of relatively high socio-economic status, limiting the extent to which conclusions can be drawn across different populations. Further, we cannot draw conclusions with regards to specificity for SAD in relation to other particular anxiety disorders (e.g. GAD). It is also important to acknowledge that given the small sample size and broad age range used in this study, we were unable to take into account potentially important age effects. Given recent findings that suggest that associations between anxiety and cognitions may vary across this pre-adolescent age-range (Creswell et al., 2014), it is important that future studies are sufficiently powered to explore effects across different ages. Also, although the raters did not know the diagnostic status of the children, it is possible that they may have identified symptoms of social anxiety in some of the children and been 
influenced by them when coding the videos. Finally, all children in the socially anxious group met diagnostic criteria for SAD as their primary disorder but also had high rates of comorbid conditions - consistent with findings from other studies where treatment seeking samples have been used (e.g. Kendall et al., 2010). While we took statistical precautions to account for this it is still possible that comorbidities may have had an impact on our findings.

\section{Conclusions}

While acknowledging these limitations, this study indicates that children with SAD are more likely than children with other anxiety disorders to show social behaviour difficulties, but it is unclear if this results from social skills deficits or the use of counterproductive behavioural and cognitive strategies or both. In contrast to adult SAD models, children with SAD do not appear to be negatively biased about their social performance in general. However, they may be particularly self-critical when their performance does not go well. These findings have clinical implications as they suggest that focusing on counteracting pre- and post-event social performance appraisals may potentially be inappropriate for childhood SAD. Instead, it seems that children with SAD might benefit from interventions that focus on helping them to become less critical of themselves after social interactions have not gone well.

\section{References}

Alfano, C. A., Beidel, D. C., \& Turner, S. M. (2006). Cognitive correlates of social phobia among children and adolescents. Journal of Abnormal Child Psychology, 34(2), 182194.

American Psychiatric Association. (2013). Diagnostic and statistical manual of mental disorders (Fifth ed.). Arlington, VA: American Psychiatric Association.

Beesdo, K., Bittner, A., Pine, D. S., Stein, M. B., Hofler, M., Lieb, R., \& Wittchen, H. U. (2007). Social anxiety disorder: patterns of incidence and secondary depression risk. European Neuropsychopharmacology, 17, S511-S512. doi:10.1016/s0924$977 \times(07) 70788-5$ 
Beidel, D. C., Turner, S. M., \& Morris, T. L. (1999). Psychopathology of Childhood Social Phobia. Journal of the American Academy of Child \& Adolescent Psychiatry, 38(6), 643-650. doi:http://dx.doi.org/10.1097/00004583-199906000-00010

Beidel, D. C., Turner, S. M., \& Morris, T. L. (2000). Behavioral treatment of childhood social phobia. Journal of Consulting and Clinical Psychology, 68(6), 1072.

Brozovich, F., \& Heimberg, R. G. (2008). An analysis of post-event processing in social anxiety disorder. Clinical Psychology Review, 28(6), 891-903.

Cartwright-Hatton, S., Tschernitz, N., \& Gomersall, H. (2005). Social anxiety in children: social skills deficit, or cognitive distortion? Behaviour Research and Therapy, 43(1), 131-141.

Clark, D. M. (2005). A cognitive perspective on social phobia. In W. R. Crozier \& L. E. Alden (Eds.), The essential handbook of social anxiety for clinicians (pp. 193-218). West Sussex: John Wiley \& Sons, Ltd.

Clark, D. M., \& Wells, A. (1995). A cognitive model of social phobia. In R. G. Heimberg, M. Liebowitz, D. Hope, \& F. Schneier (Eds.), Social phobia: Diagnosis, assessment and treatment (pp. 69-93). New York: Guilford Press.

Cole, D. A., Jacquez, F. M., \& Maschman, T. L. (2001). Social Origins of Depressive Cognitions: A Longitudinal Study of Self-Perceived Competence in Children. Cognitive Therapy and Research, 25(4), 377-395. doi:10.1023/a:1005582419077

Creswell, C., Apetroaia, A., Murray, L., \& Cooper, P. J. (2013). Cognitive, affective, and behavioral characteristics of mothers with anxiety disorders in the context of child anxiety disorder. Journal of Abnormal Psychology, 122(1), 26-38. doi:10.1037/a0029516

Creswell, C., Murray, L., \& Cooper, P. (2014). Interpretation and Expectation in Childhood Anxiety Disorders: Age Effects and Social Specificity. Journal of Abnormal Child Psychology, 42(3), 453-465. doi:10.1007/s10802-013-9795-z

Dannahy, L., \& Stopa, L. (2007). Post-event processing in social anxiety. Behaviour Research and Therapy, 45(6), 1207-1219. doi:http://dx.doi.org/10.1016/j.brat.2006.08.017

Donovan, C. L., Cobham, V., Waters, A. M., \& Occhipinti, S. (2015). Intensive Group-Based CBT for Child Social Phobia: A Pilot Study. Behavior Therapy, 46(3), 350-364. doi:http://dx.doi.org/10.1016/j.beth.2014.12.005

Erath, S. A., Flanagan, K. S., \& Bierman, K. L. (2007). Social anxiety and peer relations in early adolescence: Behavioral and cognitive factors. Journal of Abnormal Child Psychology, 35(3), 405-416.

Gavric, D., Moscovitch, D. A., Rowa, K., \& McCabe, R. E. (2017). Post-event processing in social anxiety disorder: Examining the mediating roles of positive metacognitive beliefs and perceptions of performance. Behaviour Research and Therapy, 91, 1-12. doi:http://dx.doi.org/10.1016/i.brat.2017.01.002

Ginsburg, G. S., Sakolsky, D., Piacentini, J., Walkup, J. T., Coffey, K. A., Keeton, C. P., . . McCracken, J. T. (2011). Remission after acute treatment in children and adolescents with anxiety disorders: Findings from the CAMS. Journal of Consulting and Clinical Psychology, 79(6), 806-813. doi:10.1037/a0025933

Halldorsson, B., \& Creswell, C. (2017). Social anxiety in pre-adolescent children: What do we know about maintenance? Behaviour Research and Therapy, 99, 19-36.

Halls, G., Cooper, P. J., \& Creswell, C. (2015). Social communication deficits: Specific associations with Social Anxiety Disorder. Journal of Affective Disorders, 172(0), 3842. doi:http://dx.doi.org/10.1016/j.jad.2014.09.040 
Heimberg, R. G., Brozovich, F. A., \& Rapee, R. M. (2010). Chapter 15 - A Cognitive Behavioral Model of Social Anxiety Disorder: Update and Extension. In S. G. Hofmann \& P. M. DiBartolo (Eds.), Social Anxiety (Second Edition) (pp. 395-422). San Diego: Academic Press.

Hinrichsen, H., \& Clark, D. M. (2003). Anticipatory processing in social anxiety: Two pilot studies. Journal of Behavior Therapy and Experimental Psychiatry, 34(3), 205-218.

HMSO. (2005). The National Statistics Socio-Economic Classification User Manual. Basingstoke: Palgrave MacMillan.

Hopko, D. R., McNeil, D. W., Zvolensky, M. J., \& Eifert, G. H. (2002). The relation between anxiety and skill in performance-based anxiety disorders: A behavioral formulation of social phobia. Behavior Therapy, 32(1), 185-207.

James, A. C., James, G., Cowdrey, F. A., Soler, A., \& Choke, A. (2015). Cognitive behavioural therapy for anxiety disorders in children and adolescents. The Cochrane Library.

Kendall, P. C., Compton, S. N., Walkup, J. T., Birmaher, B., Albano, A. M., Sherrill, J., ... . Piacentini, J. (2010). Clinical characteristics of anxiety disordered youth. Journal of anxiety disorders, 24(3), 360-365. doi:http://dx.doi.org/10.1016/j.janxdis.2010.01.009

Kendall, P. C., \& Hedtke, K. A. (2006). Coping Cat workbook. 2nd. Ardmore, PA: Workbook. Kessler, R. C., Berglund, P., Demler, O., Jin, R., Merikangas, K. R., \& Walters, E. E. (2005). Lifetime prevalence and age-of-onset distributions of DSM-IV disorders in the national comorbidity survey replication. Archives of General Psychiatry, 62(6), 593602. doi:10.1001/archpsyc.62.6.593

McManus, F., Sacadura, C., \& Clark, D. M. (2008). Why social anxiety persists: An experimental investigation of the role of safety behaviours as a maintaining factor. Journal of Behavior Therapy and Experimental Psychiatry, 39(2), 147-161.

Morgan, J., \& Banerjee, R. (2006). Social anxiety and self-evaluation of social performance in a nonclinical sample of children. Journal of Clinical Child and Adolescent Psychology, 35(2), 292-301.

Muris, P., Schmidt, H., \& Merckelbach, H. (2000). Correlations among two self-report questionnaires for measuring DSM-defined anxiety disorder symptoms in children: The Screen for Child Anxiety Related Emotional Disorders and the Spence Children's Anxiety Scale. Personality and Individual Differences, 28(2), 333-346.

Nauta, M. H., Scholing, A., Rapee, R. M., Abbott, M., Spence, S. H., \& Waters, A. (2004). A parent-report measure of children's anxiety: Psychometric properties and comparison with child-report in a clinic and normal sample. Behaviour Research and Therapy, 42, 813-839. doi:10.1016/S0005-7967(03)00200-6

Öst, L.-G., Cederlund, R., \& Reuterskiöld, L. (2015). Behavioral treatment of social phobia in youth: Does parent education training improve the outcome? Behaviour Research and Therapy, 67(0), 19-29. doi:http://dx.doi.org/10.1016/j.brat.2015.02.001

Pearcey, S., Alkozei, A., Chakrabarti, B., Dodd, H., Murayama, K., Stuijfzand, S., \& Creswell, C. (2018). Do clinically anxious children cluster according to their expression of factors that maintain child anxiety? Journal of Affective Disorders, 229, 469-476. doi:https://doi.org/10.1016/i.jad.2017.12.078

Pfeifer, J. H., Lieberman, M. D., \& Dapretto, M. (2007). "I know you are but what am I?!": neural bases of self-and social knowledge retrieval in children and adults. Journal of Cognitive Neuroscience, 19(8), 1323-1337. 
Rachman, S., Grüter-Andrew, J., \& Shafran, R. (2000). Post-event processing in social anxiety. Behaviour Research and Therapy, 38(6), 611-617.

Rapee, R. M., \& Heimberg, R. G. (1997). A cognitive-behavioral model of anxiety in social phobia. Behaviour Research and Therapy, 35(8), 741-756. doi:http://dx.doi.org/10.1016/S0005-7967(97)00022-3

Rapee, R. M., \& Spence, S. H. (2004). The etiology of social phobia: empirical evidence and an initial model. Clinical Psychology Review, 24(7), 737-767. doi:http://dx.doi.org/10.1016/j.cpr.2004.06.004

Reynolds, S., Wilson, C., Austin, J., \& Hooper, L. (2012). Effects of psychotherapy for anxiety in children and adolescents: A meta-analytic review. Clinical Psychology Review, 32(4), 251-262.

Scharfstein, L. A., \& Beidel, D. C. (2015). Social skills and social acceptance in children with anxiety disorders. Journal of Clinical Child \& Adolescent Psychology, 44(5), 826-838.

Schmitz, J., Krämer, M., Blechert, J., \& Tuschen-Caffier, B. (2010). Post-event processing in children with social phobia. Journal of Abnormal Child Psychology, 38(7), 911-919.

Schmitz, J., Krämer, M., \& Tuschen-Caffier, B. (2011). Negative post-event processing and decreased self-appraisals of performance following social stress in childhood social anxiety: An experimental study. Behaviour Research and Therapy, 49(11), 789-795.

Schutters, S. I. J., Dominguez, M. d. G., Knappe, S., Lieb, R., van Os, J., Schruers, K. R. J., \& Wittchen, H. U. (2011). The association between social phobia, social anxiety cognitions and paranoid symptoms. Acta Psychiatrica Scandinavica, 125, 213-227.

Silverman, W. K., \& Albano, A. M. (1996). The anxiety disorders interview schedule for DSMIV - child and parent versions. San Antonio. TX: Psychological Corporation.

Spence, S. H. (1998). A measure of anxiety symptoms among children. Behaviour Research and Therapy, 36(5), 545 - 566. doi:10.1016/S0005-7967(98)00034-5

Spence, S. H., Donovan, C. L., \& Brechman-Toussaint, M. (1999). Social skills, social outcomes, and cognitive features of childhood social phobia. Journal of Abnormal Psychology, 108(2), 211.

Spence, S. H., Donovan, C. L., \& Brechman-Toussaint, M. (2000). The treatment of childhood social phobia: The effectiveness of a social skills training-based, cognitivebehavioural intervention, with and without parental involvement. Journal of Child Psychology and Psychiatry, 41(6), 713-726.

Spence, S. H., \& Rapee, R. M. (2016). The etiology of social anxiety disorder: An evidencebased model. Behavior Research and Therapy, 86, 50-67. doi:10.1016/j.brat.2016.06.007

Tuschen-Caffier, B., Kuhl, S., \& Bender, C. (2011). Cognitive-evaluative features of childhood social anxiety in a performance task. Journal of Behavior Therapy and Experimental Psychiatry, 42(2), 233-239. doi:10.1016/j.jbtep.2010.12.005

Vassilopoulos, S. P. (2012). Social anxiety and memory biases in middle childhood: a preliminary study. Hellenic Journal of Psychology, 9, 114-131.

Waite, P., \& Creswell, C. (2014). Children and adolescents referred for treatment of anxiety disorders: Differences in clinical characteristics. Journal of Affective Disorders, 167(0), 326-332. doi:http://dx.doi.org/10.1016/j.jad.2014.06.028 